\title{
Collection Development Policies in Public Libraries in Australia: A Qualitative Content Analysis
}

\author{
Matthew Kelly \\ Department of Information Studies, Curtin University, Australia
}

Recommended citation:

Kelly, Matthew. 2015. “Collection Development Policies in Public Libraries in Australia: A Qualitative Content Analysis". Public Library Quarterly 34 (1): 1-19. DOI: 10.1080/01616846.2015.1000783. 


\begin{abstract}
The role that public library collection development polices play in guiding selectors and informing users has been promoted as a pillar of good professional practice. While these policies purport to open up the methods and the criteria used in selection so as to promote transparency and a sense of professional objectivity, how they actually are developed and put into practice has remained largely implicit in the research literature. This analysis revealed that policies tended to focus on local issues and remained heavily materials focused. How collections are developed to support user's information needs and substantive issues associated with topicality are largely unarticulated.
\end{abstract}

\title{
Introduction
}

Collection policies provide a direction to librarians and users on how their institution has chosen to meet the materials and information needs of its users. This process is a complex mix of factors that involve issues associated with how the library is constituted, managed and funded; how it is staffed; how staff are trained in the specific roles of materials selection and evaluation; the personal proclivities of the staff - their Weltanschauungen; the types of materials sought and their range, depth and availability.

Public libraries are faced with a need to make choices and to prioritize based on a set of defined criteria and practical procedures. Collection policies, which outline how this process is accomplished, promote a consistent and systematic approach to practice and offer a means by which libraries can plan to incorporate their users' needs into the future shape of their collection. Collection policies also promote accountability; the promise that the management of the library will meet standards that stakeholders deem to be appropriate for a tax-payer funded institution.

The research presented in this paper sought to facilitate understanding about how selection and evaluation decisions are made through a series of questions: What criteria are in use? How are they explained by libraries? Why do some libraries seem to have collections of demonstrably better quality than others?

Content analysis was chosen as a method that could enable the policies to be interpreted both through their manifest and their latent content. The analysis also was intended to provide insights into how the policies function as repositories for the hopes and the desires of the people who make the public library what it is.

\section{Literature Review}

While collection development in academic libraries has received significant attention from researchers, research on public library collection development is sporadic (Denny 1992; Smith 1995; Vergueiro 1997; Barreau 2001; Davidson and Dorner 2009). Written collection development policies are a common part of the public library landscape and are endorsed, although not entirely uncritically, by generalist commentators as an important means to guide staff and inform stakeholders (Gorman and Howes 1989; Johnson 2009; Gregory 2011; Evans and Saponaro 2012). Manuals and guidelines on how to formulate such policies are available (Hoffmann and Wood 2005; American Library Association 1989).

Not all opinion is favourably disposed to collection policies; critique as to the efficacy of such policies can be found in doubts about their intellectual foundation (Snow 1996), or in tendencies for such policies to reify (Gorman 
and Howes ibid.) - or that they simply are ignored (Davidson and Dorner ibid.). The dynamic nature of selection is often unacknowledged in collection policies; while qualitatively acceptable and representative collections might be put together by most librarians, armed with a well-appointed list or bibliography, the result would be "sterile," divorced, as such an exercise would be, from the critical consideration of the library users' needs (Denny ibid., 4).

These user needs are both aesthetic and technical in nature, with the contrast in what should take precedence a function of "deeper convictions about the nature and impact of knowledge on individuals and society" (Dick 1999, 312). These priorities are the epistemic (and social) bases upon which selection and evaluation occur. Without bringing light to bear on the nature of these considerations, it is difficult to make valid claims as to the relative value of collections or the decisions that have spawned their development (Osburn 2005). How do librarians decide what is best, should they do so and what do the policies say about this critical decision in how collections are formed (Usherwood 2007, 66)?

Few attempts have been made to understand the structural properties of collection policies and how they influence practice. Smith investigated a selection of public libraries and found a significant discrepancy between the criteria that were listed for selection and the actual mechanisms of the selection process. Smith is critical of libraries abdicating selection responsibilities to commercial interests and approaching selection passively and concludes that, given the results of her study, "there does not appear to exist a consistent professional view of, and approach to, selection which could be further consistent with some kind of professional ethics or standards of selection" (Smith 1995, 93). Mangrum and Pozzebon $(2012,113)$ conducted a content analysis on how collection development policies in a sample of academic libraries address issues associated with electronic resources. They reported favourably on the comprehensiveness of the policies they studied to guide decision making and emphasised the importance of ensuring that they were regularly maintained as a publicly-available "shared frame of reference" detailing how decisions are made.

\section{Methodology}

The research utilised qualitative content analysis to interrogate the data in a systematic way that allowed the emergence of both manifest and latent content. It also allowed comparison of the data through an inductive approach, primarily the constant comparative method. Qualitative Content Analysis was chosen as it is an accepted method within LIS; it aims to describe phenomena so that they may be understood contextually rather than objectively (Domas White and Marsh 2006, 38).

The sample was limited to public libraries servicing populations of between 200,000 and 350,000 with publicly available collection policies. The libraries in the sample did not include the largest municipal library systems in Australia but did include those of significant size and complexity. Their capacity to support relatively sophisticated collection development was the main reason for their choice. Of the 24 libraries identified, seven had published collection policies on their website when accessed in October 2012. These libraries' policies were the basis of the present study.

A framework for coding was developed based upon investigation of the literature on collection development and management, and public libraries. A pilot project was undertaken using the Casey Cardinia Library Corporation Collection Development Policy (2011) as the subject of analysis. This policy was chosen as it was the most detailed of the sampled policy documents and contained significant referencing to collection management research. The 
policy was selectively coded for instances in which selection, evaluation or users were discussed. Memo writing, from the coded policy, expanded the list of topics that could be considered. An initial coding framework of categories emerged inductively from a combination of a priori concepts, and the content of the collection policy, and was discussed with a conversant (a PhD holder in LIS) to facilitate validation of the coding scheme. The conversant's suggestions led to re-evaluating how the collection criteria differed from the community criteria and how collection-specific activities and management processes could be represented more accurately in the coding framework.

A decision was made to code the documents in their entirety (minus administrative data and appendices) using a descriptive/topical coding method (Saldana 2009). This choice was made to ensure that all data was accounted for and that the important selection, evaluation and user-oriented material was contextualized with other matters included in the collection policies. Units of analysis were chosen primarily at a semantic level.

As themes emerged during coding, new categories were developed and others reconceptualized in order to account for the way that the documents emphasized the content. Some categories were amalgamated with others and some were made redundant as they did not reflect the content of the documents. The iterative process involved several changes to the coding framework and the development of a domain-level conceptualization that allowed for the broader implications of the categories to be contextualized .

Once the final coding framework was developed, all documents were re-coded to match the updated categories. During the process of coding, a coding book was maintained which documented reasons for the changes that were made, examples of how units of analysis were coded and reasons why particular categories were deemed more appropriate than others. A sample document was sent to an experienced librarian with a coding manual to assist with verification.

Once all of the policies had been coded and results tabulated, they were compared to ascertain similarities and differences in emphasis. In the interpretive aspects of the content analysis that followed, the quantitative frequencies were utilized as a means by which the data from the sample could feed back into the questions that stimulated the research, provide new perspectives upon the questions and open up other, collateral, opportunities for inquiry (Mayring 2000). In utilising the conceptual structure that emerged from the texts as the framework for analysis, the aim was to elucidate a sense of how the policies sampled reflect the practices in public library collection policymaking.

The discourse on collection development in the policies provided a means by which to test how the sampled documents described, constrained and encouraged activity in certain directions and not in others. These selection activities express a framework of meaning. As meaning in this context changes so does the social life (in this case of the library user) change (Altheide 1996, 69). The research method used in the study provided a means to help elicit understanding of how the library collection policy operates to influence the activities of collection librarians, specifically in terms of the types of selection, evaluation and user-focused activities that it calls upon them to undertake.

\section{Results}

The content of the collection policies was categorized into six main themes. A seventh theme was added aggregating five areas that were found to have lesser emphasis but were still considered significant (Social Equity, Community Characteristics, Educative Concerns, Collection Theory, Library Association 
Policies).

All of the six main themes have direct significance to selection, evaluation and the representation of user needs and interests except for Management Planning and Budgeting which has only an indirect relationship. Management Planning and Budgeting is described here so that the significance of non selectionrelated material within collection policies can be appreciated. The themes revealed by the research, in order of priority, are outlined below.

\section{Selection Methodologies (reasons for inclusion and exclusion)}

Utilising content analysis methods to characterize materials choice in a systematic way enabled disparate approaches, and highly-topical variations on the theme of selection, to be brought together in one category. By separating a selection methodology from the other materials-centered selection and evaluation criteria, the emphasis that policy developers placed on these highlyspecific descriptions could be better defined. This category revealed the ubiquity of idiosyncratic and locally-defined ways of describing practice in selection. Silverman's (2009) content analysis approach to documents in the finance industry revealed a similar tendency for technical and idiosyncratic terminology to proliferate in a community of practitioners. Only two policies did not emphasize these types of concerns as the primary emphasis in their published documents. In their case they both emphasized-in simply quantitative terms-Management Planning and Budgeting. Hardesty and Mak's (1994) discussion of the possibility of a core collection in undergraduate libraries outlined how faculty selection choices are similarly idiosyncratic.

Given the strong representation of the Selection Methodology category across most sampled documents, a further content analysis was conducted on the 266 coding units identified from the sample. These yielded seventy-nine categories. These categories, which are reasons for inclusion or exclusion, varied widely, as might be expected. The first category was Australian Content and the last was Realia (exclude). For $68 \%$ of the categories, a reason for inclusion or exclusion was recorded extremely rarely, on only one or two occasions.

This secondary content analysis revealed further characteristics relating to how public libraries select and explain selection. These categories would not have emerged from the data without use of a coding approach-their specificity would have ensured their categorization was overlooked as either too trivial or too idiosyncratic to warrant reporting. For both of the subcategories Australian Content and Local and Regional Focus the Professional Judgment category, which included considerations of relevance, might have been selected. In the case of the most prevalent sub-category, Recommendations from Staff or Community, the Demand and Circulation category might also have been selected. Taken together, the three subcategories-Australian Content, Local and Regional Focus, Recommendations from Staff or Community - seemed to be worthy of separate consideration in any further development of the research to help better define whether decisions are parochially oriented, or, if they are based on attempting to collect the truly relevant for the user community.

\section{Management Planning and Budgeting}

This category could well be said to be of equal importance to Selection Methodologies in terms of the substantive coverage that the policies devoted to it. For two policies it ranked highest and for another four it was the second most common category coded. Only one library did not rank this category in its top four categories for coded content, and that was because of its extensive detailing of materials-centered selection and evaluation issues. This category was formulated to encompass all organizational and political issues that were not associated with Social Equity. As such, its focus was very broad. What the 
analysis revealed was that collection policies are often used as a communications tool for public libraries to explain everything they are tasked to do, and not just to deal with collections. Straw (2003) described these types of policies as non-comprehensive, not in a pejorative sense, but so their focus can be differentiated from detailed plans. To understand how policies can truly make a difference in the quality of a collection we should factor in their rhetorical quality and how they serve as communicative devices (Atkinson 1986, 148).

This category divided the genuine collection concerns (range, depth, currency etc.) from other significant matters that may only slightly impact the quality of materials in a collection. Coding a unit of text from a policy document that promises to support recognising changing needs and responding flexibly is an example of policy in action rather than collection practice in action. It is important that statements of this kind in collection policy documents should be specifically identified so that the useful selection, evaluation and user-oriented practices that are described can be partitioned off from less-relevant managerial content.

Focus on matters associated with administration and management to the exclusion of collections has a long history in library-oriented discourse. In reporting the results of a bibliometric analysis of one year's journal articles listed in Library Literature, Saračević and Perk $(1973,135)$ concluded that

Management of people, resources and systems was a major concern as opposed to concerns with literatures and even less to concerns with professional library processes. This [minimal focus] may reflect a fact that after administration is dispensed with there is not that much effort expended in creation of knowledge and general education.

Lee $(2005,67)$ advanced the view that a managerial association with collections has been a dominant theme in collection development considerations, associating it with issues of control; the collection concept is not sufficiently defined and "represents many different entities that are often seen from a library management perspective rather than from the perspective of users."

\section{Collection Range and Depth}

While it may seem to be a normative expectation that public libraries would seek to hold a comprehensive range of materials this is not, in fact, a reasonable expectation. Public library non-fiction holdings in Australia seem to be nearly always governed by the triumvirate of publisher, supplier, approvalplan. The selection result, on the whole, is serendipitous, especially when selection is rarely a full-time occupation (Johnson ibid., 38). Selection by exception to an approval plan might be a more worthy characterization of what actually occurs (Gregory ibid., 56). Sensible delineations of how to work with approval plans do exist. Carpenter (1989) suggests that the approval plan should provide the basis for the collection policy. Vickery $(2004,341)$ believes that "the real written policies, at least for books, are approval plan schedules."

Collection policies leave us with quite a different impression of how the process of selection takes place. None of the policies surveyed provided sufficient information to be able to ascertain if an evaluation of the collection had actually ever been done, and if so, when and how. The City of

Onkaparinga Libraries Collection Development Policy (2010) came the closest in highlighting some type of process for evaluation of range and depth through reference to the absolute numbers of items in a range of categories and a discard age schedule for adult non-fiction items using Dewey Decimal 


\section{Classification ranges.}

Several commentators advocate that collection evaluation precedes selection. Carrigan (1996) suggested that as a starting point the style of collection practice rather than the nature of the collection should be investigated. With this principle in mind, he noted that ascertaining over-selection was the key to delimiting the poorer choices that selectors may make. Edgar $(2003,400)$ pointed to how that the collection plan "essentially exists to identify and close the gaps between the collection's current strengths and weaknesses and the desired strengths and weaknesses." Only four of the seven policies sampled in this study canvassed the possibility that their collections might contain gaps or weaknesses. Given this finding, it should not be surprising that trust in librarians' knowledge of their collection, and how it is likely to be used, remains an accepted (but not necessarily acceptable) means by which libraries delegate collection duties (Corrigan 2005).

Discussions of collection range and depth are normal parts of collection policies and were significant in the sample documents for this study as they were in Smith's (ibid.) similar study. The emphasis in this study largely fell in the same range as Smith's study as well (the third most important consideration). The discussion of this category rarely approached any significant descriptive form that might allow an interested party to know what criteria are actually used. In nearly all situations there was very little indication of what the library meant when it pointed to issues of range and depth. This observation was also consistent with Smith's findings. While lack of clarity associated with definitions of range and depth is likely to be of only passing inconvenience to a library user, if the document aims to inform staff it would seem to result in potentially serious consequences for how the collection develops.

The policies studied could not provide users with a transparent analysis of how the collections compared against their own self-evaluation or against any type of peer standard. While collecting libraries routinely acknowledge that these standards can be assessed, the public library actually operates on a different model of accountability. Were this to be based upon a strict desire to simply turn over materials as quickly as possible public libraries might reasonably be considered exempt from scrutiny, but that is not the case. Of the sampled libraries, one provided a discard schedule which made clear that ten years is not an unusual period of time for items to remain in a circulating collection.

\section{Professional Judgment}

This grouping was highly significant as a criteria within the collection policies published by two libraries, where within the coding framework, it ranked second highest in their coded categories. Another two libraries ranked it third. It was not ranked in the top four for the remaining three libraries. By momentarily putting to one side the highly variable category Selection Methodologies and the essentially non selection-related Management Planning and Budgeting, we are left with the Collection Range and Depth and Professional Judgment categories as explicit ways of understanding the core concern relating to selection and evaluation. While it may seem mundane to describe collections policies as constituting such themes, they are not necessarily natural categories for formulating collection policies.

Professional Judgment was one of the criteria that developed as an amalgam of several themes that emerged from both the literature and the seven policies sampled in this study. Smith's research highlighted authoritativeness, accuracy, local content and format as common themes among the ten libraries that she surveyed. Two of Smith's themes, authoritativeness and accuracy, were also recognized in this study but were amalgamated into the criterion of 


\section{Professional Judgment.}

This criterion primarily related to active use of staff judgment on an issue of importance. It may have been more highly ranked had many of the multiple elements associated with it not been incorporated into the somewhat generic category Selection Methodologies. Examples of themes aggregated into the Selection Methodologies category include: Multiple Criteria (relevance and demand); Topicality (general interest); Topicality (usefulness); Highlytechnical or Highly-specialized materials (exclude). These obviously involve professional judgment, but as the aim of the study was to contribute to a better understanding of selection and evaluation, they needed to be prioritized. Unlike the conclusions drawn by Smith relating to consistency in selection, this research interprets the similarity of the emphases in the policies on currency, relevance, authority and accuracy as reflective of a robustness in, at least, this one area of selection. Any difficulties with selection and evaluation are unlikely to be located here.

Weaknesses emerged in how the various expressions of these judgements are explained in the policies. If they are not explained, is it that it is not important to do so, or that the methods are common-sense aspects of practice that do not require detailed explanations of how the competency becomes entwined with the tasks and problems of practice? The decision-making aspects, relating to highly-technical or subjective criteria, are potentially the most difficult areas in which librarians are to provide descriptive practical information on. How can it legitimately be said that a particular item is not relevant to a library with 50,000 active borrowers? Can such a judgment have meaning beyond a literary or quasi-sociological judgment or as an indication of the workings of some abstruse information theory? When we look to a library that primarily values the currency of materials, we should ask what degree of judgment about accuracy and authority is required given these foundational parameters. In the research sample, this judgment marker seemed universally absent.

\section{Discerning Materials Standards}

The emphasis on Discerning Materials Standards among the sample policies was unexpected. In one library's policy this category was coded at the second highest frequency, while coding for two other libraries saw it ranked as their third most prevalent concern. Format of materials was a significant concern in the policies surveyed and may be attributable to the interest from the public in the ability of the library to meet a significant cultural need for at least some non-monograph collections. There is also the relative ease of categorising collections by format over content that may explain its focus. Much can be, and seems to be said, about formats, while little is said about content. This is surely a problematic situation for a profession which assumes the content classification and organization of knowledge as one of its core tenets.

\section{Balancing Collection Priorities / Demand and Circulation}

The final categories that were significantly represented dealt with Balancing Collection Priorities and a category that was created through amalgamation during the research's iterative cycle of category development-Demand and Circulation. Prioritising areas of a collection for growth, or reduction in emphasis, is integral to the collection planning process (Barreau ibid.; Genoni 2004; Myall and Anderson 2007; Picket et al. 2011), but how this should be done, and on what parts of a collection it should focus, was almost universally absent from the sampled policies. Similarly, while focusing on user demandas needs, interests or popular literature - was acknowledged in all policies, the detail was largely ephemeral; how demand was assessed and how the problem of inferring need from circulation statistics might be countered was not explored. 
While demand was acknowledged as a central concern, the collection development criteria did not articulate the role that demand played in material selection practice. While some libraries indicated that they undertook "stock takes" (assessing materials inventory with specific criteria), which would have provided opportunities for evaluation to take place, only one library indicated a schedule for replacement based upon subject ranges in a classification scheme. One library provided a goal for ensuring that a certain percentage ( 75 per cent) of materials were less than ten years old.

\section{Social Equity, Community Characteristics, Educative Concerns, Collection Theory, Library Association Policies}

The remaining categories amalgamated here were far less significant in terms of representation in the sampled policy documents. It seemed that the inclusion of these categories in collection policies represented an attempt to cover the field in the organizational, political and professional domains. While this may have become a relatively orthodox approach for public libraries, it is not how all libraries construct such policies, and there seems no reason that such an approach should become normalized.

While the focus on social equity, community characteristics and library association policies are all worthwhile considerations, they provide little direction to collection development practice. Policy formulators might consider looking at broader concerns that deal with issues of educational authenticity, that is, how can users benefit from their construction as a group of cultural or informational citizen-consumers (Manning 1997)? Linked to this process might be a renewal of the type of discourse that celebrates the progressive and competent civic culture that supports local cultural institutions and how collection theory can be better aligned to the needs of selecting and evaluating to meet user needs.

\section{Discussion}

\section{Users, their materials and organizational mediation}

All collection policy documents were found to strongly emphasize the materials-centered selection and evaluation issues that form a core part of how information is organized. This is consistent with the findings of Mangrum and Pozzebon (ibid.) whose analysis of academic libraries' collection development policies also highlighted the prevalence of content as the major criteria in the collection policies they studied. In the present study, the organizational and political issues underpinning the operation of public libraries were given far greater treatment than issues associated with users, and with how theoretical or professional matters influenced or impacted public libraries' collection development activities. Materials-centered categories were, on the whole, significantly represented in ways that user-centered categories were not. While the sample revealed that library policies declared a desire to select for users, they actually dealt almost entirely with matters associated with the ways that materials are compared against other materials that may be selected.

While the selection methodologies that libraries used in the sample were materials-centered in orientation, they often revealed a genuine concern for meeting users' needs. Recommendations are a particularly significant means by which libraries in the sample polices selected for collections, and while these may be recommendations from users, they are not a user-centered approach to dealing with the selection dilemma. Users can recommend materials, but they do not recommend based upon any well-developed criteria of general use. 


\section{Alternative collection development streams: locally-defined or systematized methods}

The sample policies represented selection as an intricate activity that involves, primarily, an intuitive or impressionistic approach to materials. Consideration of materials as materials involves a considerably larger proportion of the reasoning underlying the rationale of collection development than attempts to link the practice to either the particular or general needs of library users. The collection policies surveyed largely contained reasons for the inclusion or exclusion of materials but these reasons rarely involved any systematic approach to collection development.

When selection methodologies focus on recommendations, local content, format and availability, librarian selectors miss the opportunity to discuss how they are selecting for the user. In the context of providing more relevant content, public libraries may consider providing greater focus on quality indicators for collections: turnover of stack, age of collections and client satisfaction (AEC Group 2007, 41). Generic reasons for inclusion and exclusion will only go so far in explaining how these worthwhile aims can be achieved.

\section{What should public libraries be disclosing about their collections?}

Based upon the sample studied, which should have revealed how moredeveloped Australian public libraries approach collections, it seems fair to say that methods for assessing collection range and depth are undeveloped in Australia's public libraries. Relatively simple methods are available to enable librarians to obtain an adequate understanding of how their collection compares to similar libraries based upon holdings (Lesniaski 2004). None of the libraries sampled chose to evaluate their collections using a viable method such as conspectus (Clayton and Gorman 2002), or more innovative methods such as those outlined by White (2008). The public libraries surveyed seem not to be adequately equipped to evaluate their collections beyond quite simple and, as Meera (1999) terms it, "impressionistic" criteria.

While public libraries talked about collection range and depth it would seem that what they mean is balancing collection priorities, or, the ability to ensure for every reader his or her book (a la Ranganathan). While we should not expect public libraries to "collect," we should expect that they accommodate all types of readers, and this necessitates understanding how the collection meets user needs, even when these needs are sophisticated in nature. Given the lack of programmatic approaches to understanding how individual subject areas have been selected, we might be forgiven for assuming that the state of the average public library collection, as a whole, is likely to be, also, relatively unclear.

The collection policies in this sample largely create the impression of a wellunderstood collection. In the absence of descriptions about resources and methods to provide selection guidance this seems hard to justify. Similarly, evaluation is unlikely to be qualitatively-based, either from a materials perspective or from a user perspective. Ideally, it would be based upon a combination of the two. Libraries might also look to how audience-level analyses of the collection and use of OCLC's WorldCat-derived evaluation tools (O'Neill et al. 2008) can provide insight to select for their users'distinct characteristics.

\section{Ways to move forward: building on professional strength and competence}

Professional judgment is approached with considerable clarity and consistency 
in the policies that were the subject of this sample. The epistemic objectives inherent in developing collections, through formation and disaggregation, are significantly recognized by public librarians, as are the trade-offs between privileging discourses of power and discourses of reliability (Fallis 2006). Lincoln (1997) describes the need for a contextual approach between the mechanical, or systemic, methods for selection and those that retain the myriad of title-by-title decisions that may be necessary. The latter is important, but ought to be based upon an approach that is discoverable and able to be properly articulated. These factors seem to be consistently omitted from collection policies despite the fact that they are likely to be implicit aspects of practice, albeit ones that lack a recognizable language to cross the boundary between practitioner, stakeholder and user. As Hjørland (1997) makes clear, epistemic interest should be made visible.

This study's findings indicate that collection policies strongly endorse professional judgment as a selection practice and are, in this respect, consistent with Mangrum and Pozzebon's (ibid.) findings. Usherwood's (ibid.) survey research showed that librarians, when asked to rate a level of agreement to the statement "the professional librarian who knows what quality is should be mainly responsible for what is selected for the library" disagreed 67 per cent of the time. While the librarians who created the policy documents at the centre of the research reported on in this paper may have been uncomfortable with their professional judgment being characterized as "knowing what quality is," it is telling, also, that a majority of librarians surveyed by Usherwood (through their policy documents) did not favour handing the reins of selection over to users. Usherwood's analysis supports the view that professional judgment links in with notions of how civil society-oriented cultural values can be maximized, through public library collections, to assist with the development of critical thinking skills.

\section{Creating realistic and definable collection priorities to meet all user's needs}

Balancing of collection priorities has been a central theme in how selection takes place. Collection librarians must make choices about how the library balances user demand with comprehensiveness, differing perspectives on issues and the relative weight of investment by user category, materials format and combinations of the two (Cherepon Sankowski 2003; Lines Andersen 2003; Hitchcock 2005). It is worth considering the implication of this balancing function in selection/evaluation having the lowest priority among the materials-centered issues that were analysed in this study? While approaching collection policy development as a worthwhile means to ground and guide practice may seem a proper ordering of theory with praxis, we should not expect that all will agree that selecting and evaluating with reference to a policy is desirable, and not all will be prepared to have their reasoning scrutinized. The lack of focus may indicate that some libraries consider it is better to avoid the debates and discursivities that focusing on it may engender. Most policies acknowledge that selectors are balancing competing demands from users but the references are brief and rarely provide any information on how it is done.

It is worth noting how one library's policy emphasized this part of the collection role somewhat more fulsomely. Its policy explicitly argued that collections need to be developed in a co-ordinated way; they have to be shaped to meet the needs of groups within the community who require a more proactive approach to materials selection and selection practice needs to be mindful of the broader context of materials availability; with both current and potential interest factored into selection. Selection, in a very general sense, needs explaining. 
Knowing whether the informational, cultural or recreational need is being selected for, or more likely, that a balance is being sought, can enable evaluation of the collection to be conducted with reference to the aims for its development. Explaining how collection priorities are balanced enables a more targeted evaluation of the collection as a whole. Better evaluation should enable more targeted selection and the optimal use of finite resources. Policies should discuss collection parameters: the way that branches differ in shelved holdings; when will replacement be considered for items; are the classics supporting the popular material (or vice versa); how do value and appeal impact decision making and, if applicable, to what extent do format and resources issues limit the choices that can be made. Only one surveyed policy outlined these parameters.

\section{Integrating demand into selection planning}

Discussion of the effect of demand on selection in the sampled policies was rare and it was also proportionally insignificant in terms of the broader issues that the policies covered. One library's policy focused on demand to a greater extent than other sampled policies and it focused on meeting the needs of the housebound; describing its collection as a living collection that responded to recognized needs; unashamedly locating demand as the only really significant factor in how certain categories were selected and partitioning highly technical and specialized literature from the purview of selectors.

Some of the ways that demand is defined in this study result in its expression being categorized outside of the user-centered paradigm and into materialscentered categories; for example, Local Appeal and Feedback has largely been subsumed into Selection Methodologies and General Recognition (as authority) and Currency and Relevance have likewise been taken to be indicative of Professional Judgment. This may have been of greater concern to how the study interpreted the policies' representation of selection, evaluation and user's interests had references to circulation-the cognate term to demand in the category Demand and Circulation-been seriously considered in the policies. In this sample, circulation was not a significant factor explored by the libraries' collection policies.

While not all practices and procedures should be explained in detail in a collection policy, passing reference does not constitute valid treatment. Based upon the sampled policies, it would seem that how circulation impacts upon planning to meet user needs, and how it fits within a more expansive theoretical framework needs more definition. How are the statistics that the libraries collect used in evaluation? Knievel et al. $(2006,35)$ conspectusmapped a collection and compared the results by subject headings to "overall holdings, transactions per item, percentage of collection circulated, and a ratio of ILL holdings to requests." The information gleaned from each of these methods potentially provides a range of valuable information for selectors that can help facilitate planning to meet particular user's needs.

Only by testing the collection using multiple sources of data can an accurate assessment of the state of collections be made (Knievel et al, ibid, 47). While assessments of this type of data, such as those made by Knievel et al. and Danielson $(2012,95)$ are often associated with academic libraries, the methods are not unknown in the public library context. Lyons (2007) discusses their use in various public library rating approaches in the United States. Assessing collections using this type of data-driven approach is, as Jensen (2012) points out, very different from a conspectus-driven approach. Explaining how an integrated method of selection and evaluation should be practiced does not seem to have become, as yet, the standard to which collection policies aspire. Further research is warranted on how policies can better reflect the rich methods available to libraries to select and evaluate with their users' needs in 
mind.

\section{Conclusion}

The results of the content analysis conducted on this sample of collection development policies reveal a marked tendency to explain the multitude of selection decisions through reference to the importance of local topics, local content and content creators, and the recommendations of local people. The emphasis on a wide range of selection and evaluation methodologies relating to reasons for including or excluding materials was matched by a significant tendency for the policy documents to focus on organizational and political issues, specifically those relating to management planning and budgeting. The emphasis on collections in terms of their range and depth was an important, but second order priority, that could be grouped in terms of the emphasis that the documents exhibited, with the exercise of professional judgment.

Perhaps the most surprising aspect of the content analysis was how little emphasis was given to the importance of user-centered selection and evaluation methodologies. There was certainly a significant number of references to meeting the needs of users and selecting for demand, but when coded, these references effectively disappeared within the documents; the message became muffled and only faintly discernible.

Given the strong push toward promoting user-centered selection and evaluation methodologies for library collections, the emphasis of the sample range was overwhelmingly materials-centered in how it approached and how it explained collection development. This is not to say that user needs were marginalized in these policies, the opposite was true. What the sample revealed, it would seem, is the inevitable result of policies focused on materials rather than access. While it is remains easier to describe the collection than its users' needs, libraries with commitment and imagination should look to the fertile possibilities for how they can communicate to internal and external audiences the truly stimulating part of what they provide - opportunity for people to use the collections. The potential for how this use might be represented in policy documents to aid practitioners and other interested stakeholders to understand collection management, seems to be, as yet, less than fully developed.

\section{Reference List}

AEC Group. 2007. Structural Reform in Public Library Services in Western Australia: Final Report. Perth: Local Government Association and Government of Western Australia.

American Library Association. 1989. Guide for Collection Policy Statements. Chicago: American Library Association.

Altheide, David. 1996. Qualitative Media Analysis. Newbury Park: Sage.

Atkinson, Ross W. 1986. "Selection for Preservation: A Materialistic Approach." Library Resources and Technical Services 30 (4): 341-353.

Barreau, Deborah. 2001. "Information Systems and Collection Development in Public Libraries." Library Collections, Acquisitions, and Technical Services 25 (3): 263-279.

Carrigan, Dennis P. 1996. "Collection Development-Evaluation." The Journal of Academic Librarianship 22 (4): 273-278.

Corrigan, Andy. 2005.'The Collection Policy Reborn: A Practical Application of Web-Based Documentation." Collection Building24 (2): 65-69. 
Carpenter, Eric J. 1989. "Collection Development Policies Based on Approval Plans." Library Acquisitions: Practice \& Theory 13 (1): 39-43.

Casey Cardinia Library Corporation (2011) Collection Development Policy, 2011.www.cclc.vic.gov.au/collection\%20development\%20policy\%2020 $\underline{11}$

Cherepon, Lois, and Andrew Sankowski. 2003. "Collection Development at SJU Libraries: Compromises, Missions, and Transitions." The Acquisitions Librarian 15 (30): 63-75.

City of Onkaparinga Libraries. 2010. City of Onkaparinga Libraries Collection Development Policy 2009/2010. www.onkaparingacity.com/custom/files/docs/collection_management_po $\underline{\text { licy.pdf }}$

Clayton, Peter, and Gary E. Gorman. 2002. "Updating Conspectus for a Digital Age." Library Collections, Acquisitions, and Technical Services 26 (3): 253-258.

Danielson, Robert. 2012. "A Dual Approach to Assessing Collection Development and Acquisitions for Academic Libraries."Library Collections, Acquisitions, and Technical Services 36 (3): 84-96.

Davidson, Glenn, and Dan Dorner. 2009. "Selection Criteria for Mobile Library Collections." Collection Building 28 (2): 51-58.

Denny, Carolyn Ann King. 1992. "The Development of a Statistical Assessment Methodology for Collection Management in a Public Library." Master's Theses, Paper 515. http://scholarworks.sjsu.edu/etd theses/515/

Dick, Archie L. 1999. "Epistemological Positions and Library and Information Science." The Library Quarterly 69 (3): 305-323.

Domas White, Marilyn and Emily E. Marsh. 2006. "Content Analysis: A Flexible Methodology.”Library Trends 55 (1): 22-45.

Edgar, William B. 2003. "Toward a Theory of Collection Development: An Activities and Attributes Approach." Library Collections, Acquisitions, and Technical Services 27 (4): 393-423.

Evans, G. Edward, and Margaret Z. Saponaro. 2012. Collection Management Basics. $6^{\text {th }}$ Ed. Santa Barbara: Libraries Unlimited.

Fallis, Don. 2006. "Social Epistemology and Information Science.” Annual Review of Information Science and Technology 40 (1): 475-519.

Genoni, Paul.2004. "Content in Institutional Repositories: A Collection Management Issue." Library Management 25 (6/7): 300-306.

Gorman, Gary Eugene and Brian R. Howes. 1989. Collection Development for Libraries. London: Bowker-Saur.

Gregory, Vicki L. 2011. Collection Development and Management for 21st Century Library Collections: An Introduction. New York: Neal-Schuman Publishers. 
Hardesty, Larry, and Collette Mak. 1994. "Searching for The Holy Grail: A Core Collection for Undergraduate Libraries." The Journal of Academic Librarianship 19 (6): 362-371.

Hitchcock, Leonard A. 2005. "An Examination of Article Two of "The Library Bill Of Rights'.” Public Library Quarterly 24 (2): 1-18.

Hjørland, Birger. 1997. Information Seeking and Subject Representation. Westport CT. / London: Greenwood Press.

Hoffmann, Frank W., and Richard John Wood. 2005. Library Collection Development Policies: Academic, Public, and Special Libraries. Lanham: Scarecrow Press.

Jensen, Karen. 2012. "Data-Driven Decisions for Library Liaisons: Exploring Strategies for Effectively Managing Diminishing Monograph Collections." Collection Management 37 (1): 9-22.

Johnson, Peggy. 2009. Fundamentals of Collection Development and Management. Chicago: American Library Association.

Knievel, Jennifer E., Heather Wicht, and Lynn Silipigni Connaway. 2006. "Use of Circulation Statistics and Interlibrary Loan Data in Collection Management." College \& Research Libraries 67 (1): 35-49.

Lee, Hur-Li. 2005. "The Concept of Collection From the User's Perspective." The Library Quarterly 75 (1): 67-85.

Lesniaski, David. 2004. "Evaluating Collections: A Discussion and Extension of 'Brief Tests Of Collection Strength'." College \& Undergraduate Libraries 11 (1): 11-24.

Lincoln, Timothy D. 1997. “A Contextual Approach to Collection Management in Religious Studies for North American Libraries." The Acquisitions Librarian 9 (17-18): 63-76.

Lines Andersen, Deborah. 2003. "Selling a Public Good: The Case of Rechartering Public Libraries by Referendum in New York State." Public Library Quarterly 22 (4): 5-23.

Lyons, Ray. 2007. “Unsettling Scores: An Evaluation of Hennen's Annual Public Library Ratings.” Public Library Quarterly 26 (3-4): 49-100.

Mangrum, Suzanne, and Mary Ellen Pozzebon. 2012. "Use of Collection Development Policies in Electronic Resource Management." Collection Building 31 (3): 108-114.

Manning, Kathleen. 1997. "Authenticity in Constructivist Inquiry: Methodological Considerations Without Prescription." Qualitative Inquiry 3 (1): 93-115.

Mayring, Philipp. 2000. "Qualitative Content Analysis." In Forum: Qualitative Social Research 1 (2). www.qualitative-research.net/index.php/fqs/article / view/1089/2386

Meera, B.M. 1999. "Measurement of Quality in Collection Development: Impressionistic Method of Survey At ISI Library." DRTC Workshop on Information Management, Bangalore, 6-8 January 1999. http://drtc.isibang.ac.in/xmlui/bitstream/handle/1849/258/papag.pdf?sequence $=1$ 
Myall, Carolynne, and Sue Anderson. 2007. "Can this Orthodoxy be Saved?

Enhancing the Usefulness of Collection Plans in the Digital

Environment."Collection Management 32 (3-4): 235-258.

O'Neill, Edward T., Lynn Silipigni Connaway, and Timothy J. Dickey. 2008. "Estimating the Audience Level for Library Resources." Journal of The American Society for Information Science and Technology 59 (13): 20422050.

Osburn, Charles B. 2005. "Collection Evaluation: A Reconsideration." Advances in Library Administration and Organization 22: 1-21.

Pickett, Carmelita, Jane Stephens, Rusty Kimball, Diana Ramirez, Joel Thornton, and Nancy Burford. 2011. "Revisiting an Abandoned Practice: The Death and Resurrection of Collection Development Policies." Collection Management 36 (3): 165-181.

Saldana, Johnny. 2009. The Coding Manual for Qualitative Researchers. Thousand Oaks CA: Sage.

Saračević, Tefko, and Lawrence J. Perk. 1973. "Ascertaining Activities in a Subject Area Through Bibliometric Analysis. Application to Library Literature." Journal of the American Society for Information Science 24 (2): $120-134$.

Silverman, Henry I. 2009. "Qualitative Analysis in Financial Studies: Employing Ethnographic Content Analysis.” Journal of Business \& Economics Research 7 (5): 133-136.

Smith, Lisa Lorraine. 1995. “'To Bring the Best Reading Within the Reach of All.' A Study of the Selection and Acquisitions Theory and Practice of Ten Public Library Services in Melbourne." In Public Librarianship: A Critical Nexus. Monash Occasional Papers in Librarianship, Recordkeeping and Bibliography, No. 7, edited by B.J. McMullin and R. Rasmussen, 81-96. Melbourne: Ancora Press.

Snow, Richard. 1996. "Wasted Words: The Written Collection Development Policy and the Academic Library." The Journal of Academic Librarianship 22 (3): 191-194.

Straw, Joseph. 2003. "Collection Management Statements on the World Wide Web.” The Acquisitions Librarian 15 (30): 77-86.

Usherwood, Bob. 2007. Equity and Excellence in the Public Library: Why Ignorance is Not Our Heritage. Aldershot UK / Burlington, VT: Ashgate Publishing.

Vickery, Jim. 2004. "Making a Statement: Reviewing the Case for Written Collection Development Policies." Library Management 25 (8/9): 337342.

Vergueiro, Waldomiro C.S. 1997. "Collection Development in Brazilian Public Libraries: Evolution, Perspectives and Difficulties for a Systematic Approach." Collection Building 16 (1): 4-11.

White, Howard D. 2008. "Better Than Brief Tests: Coverage Power Tests of Collection Strength.” College \& Research Libraries 69 (2): 155-174. 